\title{
Intra-follicular regulatory mechanisms in the porcine ovary
}

\author{
M.G. Hunter ${ }^{1}$ and F. Paradis ${ }^{2}$
}

'School of Biosciences, University of Nottingham, Sutton Bonington Campus, Loughborough, United Kingdom LE12 5RD; ${ }^{2}$ Department of Agricultural, Food and Nutritional Science, 4-10 Agriculture/

Forestry Centre, University of Alberta, Edmonton, Alberta, Canada, T6C-2P5

The mechanisms controlling the follicular growth continuum in the pig involve the interaction between local growth factors which are expressed throughout development and extra-follicular factors such as gonadotrophins. A large number of follicular growth factors, many belonging to the transforming growth factor- $\beta$ (TGF- $\beta$ ) superfamily, have been identified in the somatic cells and in the oocyte. The relative importance of these intra-follicular factors varies with stage of development. The initiation of follicular growth and early preantral development is controlled locally (by factors including c-kit-kit ligand, members of the bone morphogenetic family (e.g BMP-15) and growth differentiation factor-9 (GDF-9)) and gonadotrophins are not thought to be involved until later. During antral follicle development, the oocyte secretes factors that stimulate porcine granulosa cell proliferation and differentiation, modulate apoptosis and suppress progesterone production, thereby preventing premature luteinisation. Likely candidates for mediating these effects include BMP-6, -15 and GDF-9 that are critical for fertility and ovulation rate in several mammals. There are also paracrine interactions between the somatic cells, with theca derived transforming growth factor $\beta$ (TGF- $\beta$ ) playing a key role in regulating antral follicle maturation. Finally, during the periovulatory period, members of the EGF family from the granulosa cells stimulate cumulus expansion and oocyte maturation. Evidence indicates that some of these local factors may also influence oocyte developmental potential, emphasizing further the complexity, and importance, of these intra-follicular interactions.

\section{Introduction}

In many mammalian species including the pig, primordial follicle growth, once initiated, continues until the follicle either becomes atretic $(>99.9 \%)$ or proceeds to ovulation. Although the gonadotrophic regulation of antral follicle development has been studied in some detail in the pig, the role of local factors is less well known. In recent years however, significant progress has been made in understanding the complex intraovarian control mechanisms. Within the ovarian follicle, oocyte growth and differentiation depends upon an intimate association between the somatic follicular cells and the developing germ cells. An abundance of follicular growth factors, many belonging to the transforming growth factor- $\beta$ (TCF- $\beta$ ) superfamily, have 
been identified in the somatic cells and in the oocyte and are thought to be involved in the recruitment, selection and growth of follicles from the primordial stage through to ovulation and corpus luteum formation. This review will focus on the accumulating evidence that intrafollicular factors are key regulators of follicle development in the pig. Although much of the information generated in this field has come from rodent models and ruminants, we will emphasise pig data where available and integrate the available information to form conclusions relevant to porcine follicular development.

\section{The initiation of follicle growth and preantral development}

The ovarian reserve of primordial follicles is established before birth in the pig and the recruitment of resting primordial follicles into the growing pool begins during fetal life. The activation of oocytes in primordial follicles causes transformation of their surrounding granulosa cells to a cuboidal shape. Throughout gestation and post-natally there is a gradual shift in the proportions of oogenic structures within the porcine ovary - initially egg nests predominate but they decline from around day 60 of gestation whilst primordial follicles increase. Primary follicles appear from approximately day 70 , secondary follicles from birth and antral follicles from around day 60 post partum (Oxender et al. 1979). Evidence suggests that gonadotrophins are unlikely to be a critical factor for initiating primordial follicle growth (Yuan et al. 1996). The precise mechanisms controlling the initiation and the number of primordial follicles that start to grow and avoid regression are still unclear, although several growth factors, particularly members of the TGF- $\beta$ superfamily have been implicated in other species (Visser \& Themmen 2005 , Knight \& Glister 2006). The development of primary follicles to the late preantral stage involves oocyte growth, extensive granulosa cell proliferation, formation of the basal lamina and theca layer. The following sections will review the role of some of the key growth factors in early follicle development in the pig.

\section{c-kit/Kit Ligand Interactions}

The c-kit-Kit ligand (KitL) complex is a pleiotropic receptor-growth factor complex active in diverse cell systems in both the adult and the embryo. C-kit receptor is a type III transmembrane tyrosine kinase receptor expressed in the oocyte and granulosa cells, while its ligand, KitL also known as stem cell factor, is a proto-oncogene product of the granulosa cells and is expressed in the pre-granulosa cells that surround the oocyte in primordial follicles. In the fetus, it has been proposed that the interaction between c-kit and its ligand is necessary for germ cell migration to the developing gonadal ridge in mice (Keshet et al. 1991). Postnatally in the mouse, the receptor-ligand interaction may aid follicle recruitment into the pool of growing follicles (Parrott \& Skinner 1999) and in the recruitment and proliferation of theca cells from the surrounding stromal tissue (Nilsson \& Skinner 2004). Furthermore, in ovine follicles, $\mathrm{c}$-kit is expressed before the follicle stimulating hormone (FSH) receptor, suggesting that c-kit may be one of the regulatory factors preceding the actions of FSH on early follicle growth (Clark et al. 1996). In vitro studies in mice have shown that the addition of KitL to culture medium accelerates oocyte growth, and also that the oocyte can regulate KitL expression. In addition to its role in the survival of fetal germ cells and initiation of follicle growth, there is increasing support for the importance of KitL/c-kit activity for oocyte growth during preantral development (Packer et al. 1994) which may be modulated by the presence of gap junctions (Klinger \& De Felicic 2002). Evidence suggests that the c-kit ligand complex has a similar role 
in the porcine ovary. C-kit expression has been detected in all oocytes from primordial to large antral follicles, in the theca cell layer and endothelial tissue, and mRNA for KitL was found in granulosa cells of preantral and antral follicles (Brankin et al. 2004, Moniruzzaman \& Miyano 2007). Furthermore, exposure of porcine cortical tissue to KitL prior to xenografting increased oocyte survival (Moniruzzaman \& Miyano 2007). Thus it is likely that the c-kit-KitL interaction is necessary for early follicle development in the pig, as in other species, and is probably also involved in a complex regulatory loop with oocyte factors and FSH (Thomas \& Vanderhyden 2006; see below).

\section{TGF- $\beta$ superfamily}

The bone morphogenetic proteins (BMPS)

The BMP subfamily represents a relatively large subset of the TGF- $\beta$ superfamily. Bone morphogenetic proteins are synthesized and secreted as prepropeptides and are proteolytically cleaved to form mature, activated disulphide-linked dimmers (Elvin et al. 2000). The subfamily is comprised of at least 8 ligands namely BMP-2, -3, -4, -5, -6, -7, -8, and -15 and, with the exception of BMP-8, their expression has been reported in ovarian follicles of several species (Knight \& Glister 2006). These ligands are known to interact with at least 7 different receptors that can be separated into type 1 receptors including ActRIA (or ACVRI, ALK2), BMPR1A (or ALK3), BMPR 1B (or ALK6), TGFBR1 (or ALK5) and type II receptors including BMPRII, ActRII and ActRIIB (Shimasaki et al. 2004, Juengel \& MCNatty 2005). For the purpose of this review, GDF-9 and its known receptors (TGF $\beta R 1$ and BMPRII) will also be included in this section.

Transduction of the BMP and CDF-9 signal requires the formation of a hetero-oligomeric complex of a type II and a type I receptor, followed by a signalling cascade that involves the Smad proteins (see review by Miyazono et al. 2001). What makes the BMP family of such interest is that both induced and naturally occurring genetic mutations in BMP family members in mammals such as mice and sheep profoundly affect very early follicle development and ovulation rate (Dong et al. 1996, Galloway et al. 2000).

\section{Oocyte derived BMPS}

Particular focus has been given to BMP-6, BMP-15 and GDF-9 since they have been shown to be primarily derived from the oocyte and can regulate somatic cell differentiation and proliferation (Juengel \& McNatty, 2005, Gilchrist et al. 2008). There appear to be crucial species differences in the timing of expression and importance of some members of the BMP family. For example, GDF-9 is expressed in primary and later follicles in mice (Dong et al. 1996) but in contrast, is expressed by primordial follicles in sheep and cattle (Bodensteiner et al. 1999). The function of GDF-9 in primordial follicle growth remains somewhat obscure. Mice deficient in GDF-9 show an arrest in follicle development at the primary stage, the granulosa cells are abnormal with increased expression of KitL and they fail to acquire a theca layer, although oocyte growth is accelerated. Ewes with naturally occurring mutations in CDF-9 also suffer from primary ovarian failure and these results indicate a paracrine role of GDF-9 in early folliculogenesis, by regulating granulosa cell proliferation and recruitment of theca cells, while limiting growth of the oocyte (Dong et al. 1996, Nilsson \& Skinner 2002). Little is currently known about GDF-9 in early porcine follicle development, although GDF-9 expression has been detected in fetal and neonatal ovaries, albeit not to specific structures (Shimizu et al. 2004a). Evidence for a functional role for GDF-9 in the pig ovary was provided by the studies of Shimizu et al. (2004b) who injected CDF-9 gene fragments into the ovaries of prepubertal gilts and found that this increased the number of primary, secondary and tertiary follicles, concomitant with a 
decrease in the number of primordial follicles. Thus GDF-9 can promote early folliculogenesis in the porcine ovary, but whether it is obligatory or not remains unclear.

Two other TGF-B superfamily members, BMP-15 (also known as GDF-9B) and BMP-6 are selectively expressed by oocytes from early-stage mouse and sheep follicles, as for GDF-9 (Elvin et al. 2000; McNatty et al. 2005). However, unlike GDF-9, knockout of the BMP-6 gene in mice has little effect on ovarian function and BMP-15 null mice express only minor histopathological defects and are subfertile (Yan et al. 2001). Thus they do not appear to be crucial for fertility in the mouse. However, again there are species differences, as naturally occurring mutations of either the BMP-15 or CDF-9 gene have profound effects on fertility in sheep (MCNatty et al. 2005). It is hypothesized that these mutations decrease production of the mature protein or interfere with binding to cellular receptors. Ewes that are heterozygous for either of these mutations show an increase in ovulation rate, while homozygotes are infertile with follicles failing to develop beyond the primary stage due to lack of granulosa cell proliferation; on a histological level, ovaries from homozygotes show many of the same features as GDF-9 null mice ovaries (McNatty et al. 2005). Collectively, this evidence suggests that oocyte-derived GDF-9 (rodents) or both GDF-9 and BMP-15 (sheep) have critically important effects on follicular somatic (pre-granulosa and/or granulosa) cells of primordial and/or primary follicles that are essential for further follicle progression. The precise mechanisms through which this is achieved remain unclear, although it has been postulated that upregulation of KitL expression may be involved (Knight \& Glister 2006).

Although the roles of BMPs and GDF-9 in early porcine follicle development have not yet been examined in detail, work from our laboratory and others has localised BMP-15 and BMP-6 to the porcine oocyte (Quinn et al. 2002, Brankin et al. 2005a, Zhu et al. 2008) in pre-antral and antral follicles, but it is unknown how early in development expression starts and this clearly requires investigation. BMP receptors (BMPR-IA, -IB and $-I I$ ) have been identified in porcine fetal ovaries, specifically in the fetal egg nests and oocytes of primordial follicles (Fig. 1: Quinn et al. 2004a) and BMP-4, -5, and -6 have been detected in neonatal ovaries (Shimizu et al. 2004a). These data indicate that there is an active BMP system in the porcine ovary from the fetal stage onwards and indicate the potential involvement of BMPs in the formation, activation and early development of pig follicles.

\section{Somatic cell derived BMPs}

In rodents, BMP-4 and BMP-7, are expressed in theca cells from the primary/secondary stage onwards and have been shown to reduce the number of primordial follicles whilst increasing the number of primary, preantral and antral follicles (Lee et al. 2001, Nilsson \& Skinner 2003). This suggests a positive paracrine action of these BMPs on the growth of preantral follicles, as there is in antral follicles (see below). Again data on early follicle development in pigs is lacking, although as mentioned above, BMP-4 and -6 and their receptors are expressed early in development (Quinn et al. 2004a, Shimizu et al. 2004a).

\section{Anti Mullerian Hormone (AMH)}

There is compelling evidence from a number of species, particularly the mouse, that another TGF- $\beta$ superfamily member, $A M H$, plays an inhibitory role in the initiation of primordial follicle growth (Durlinger et al. 2002). In addition to its role in the differentiation of the male reproductive tract, $\mathrm{AMH}$ is expressed by the granulosa cells of the female gonad and exposure of neonatal mouse ovaries to $\mathrm{AMH}$ halved the number of growing follicles, whereas deletion of 
the $\mathrm{AMH}$ gene increased the rate of recruitment of primordial follicles (Durlinger et al. 2002, Nilsson et al. 2007). It seems likely that AMH acts at the level of the pre-granulosa/granulosa cells, as the AMH type II receptor has been localised to these cells, but not to the oocyte. AMH continues to be expressed in granulosa cells until the mid-antral stage in humans or pre-ovulatory in sheep (Visser \& Themmen 2005), implying a continuing role in follicle development beyond the primordial to primary stage. Currently, there is a paucity of information on AMH expression and its role in the growth of porcine primordial follicles.

\section{Antral follicle development}

Antral follicle development starts with the formation of the antrum, which then leads to the differentiation of the granulosa cell population into the mural granulosa cells that remain in close contact with the follicle wall, and also the cumulus granulosa cells that closely surround the oocyte. These two granulosa cell populations differ greatly in their ability to proliferate and in their steroidogenic activities. While the mural granulosa cells are actively proliferating and highly steroidogenic, the cumulus cells are in close contact with the oocyte, providing it with metabolites and other important factors necessary for the acquisition of meiotic and developmental competence. The theca cell layer, formed during the late preantral stage, is also important for the steroidogenic activity in the follicle. The following sections will review the role of key local growth factors in the regulation of antral follicle development in the pig.

\section{TGF-ß superfamily}

The bone morphogenetic proteins (BMPs)

Oocyte derived BMPS

Early studies showed that removal of the oocyte from rabbit antral follicles led to premature luteinisation of the follicle and oocyte secreted factors have now been clearly identified as negative modulators of cumulus and mural granulosa cell progesterone production (Gilchrist et al. 2008). However, the role of oocyte-secreted factors is not limited to controlling luteinisation or progesterone production but rather seems to extend to steroidogenesis in general. In pig mural granulosa cell, the oocyte was shown to stimulate $\mathrm{FSH}$-induced oestradiol production while the converse was observed in their cumulus cells (Coskun et al. 1995, Brankin et al. 2003a). In addition, similar to other species, porcine oocytes stimulate cell proliferation but also increase granulosa and theca cell viability (Hickey et al. 2005, Brankin et al. 2003a). Moreover, mouse oocytes also control cumulus cell metabolism (Eppig et al. 2005). Finally, but not least, bovine and murine oocyte secreted factors have been shown to enhance oocyte developmental competence (Hussein et al. 2006; Gilchrist et al. 2008). The latter two oocyte functions have yet to be described in a porcine model but the potential for similar roles in porcine cumulus cell metabolism and oocyte developmental competence should be investigated.

BMP-6, BMP-15 and GDF-9 have become central players in studies on the regulation of ovarian follicle growth, although it is cannot be ruled out that other oocyte factors also play a role. In the pig, similar to the other species, BMP-6, BMP-15 and GDF-9 are primarily expressed in the oocyte and are extremely abundant (Prochazka et al. 2004, Brankin et al. 2005a, Zhu et al. 2008, Lee et al. 2008, Paradis et al. 2009). Furthermore, mRNA for all three ligands and/or protein have also been detected, albeit at much lower levels, in ovarian somatic cells indicating some species differences and also the potential for somatic cells interactions. Their receptors, BMPR1A, BMPR1B, TGF $\beta$ R1 and BMPRII are expressed in all cell types in the antral follicle 
(Fig.1) indicating that these ligands may modulate the function of the mural granulosa, theca and cumulus cells (Quinn et al. 2004a, Zhu et al. 2008 and Paradis et al. 2009). In addition, Paradis et al. (2009) showed that oocyte derived mRNA for BMP-6, BMP-15 and GDF-9 as well as BMP-15 protein are expressed at constant levels throughout the follicular phase, however the expression of the mRNA for their receptors is temporally regulated (Fig.3). Interestingly, $B M P R 1 B$ mRNA abundance was positively correlated with plasma oestradiol concentrations, suggesting that the receptors may be hormonally regulated.
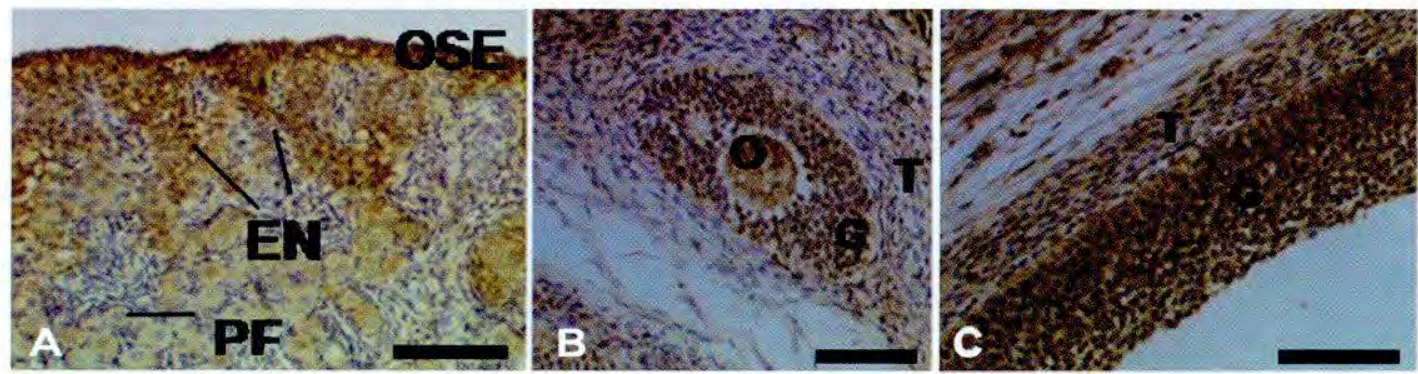

Fig. 1 Immunohistochemical localisation of the BMP receptor $1 \mathrm{~A}$ in A) fetal ovary; B) preantral follicle and C) antral follicle. PF, primordial follicle; EN, egg nests; OS, surface epithelium; O, oocyte; G, granulosa cells; T, theca cells. Scale bars $=100 \mu \mathrm{m}$.

Moreover BMP-6 and BMP-15 regulate porcine granulosa and theca cell steroidogenic activity in vitro in a manner very similar to that of the oocyte (Fig. 2; Brankin et al. 2003b, Quinn et al. 2004b, Brankin et al. 2005a, b). For example, in the granulosa cells, BMP-6 and BMP-15 consistently inhibited progesterone while increasing oestradiol production (Brankin et al. 2003b, Brankin et al. 2005a). The mechanism of action of BMP-6 on progesterone is via inhibition of the second messenger CAMP, and reduction in protein expression of steroid acute regulatory

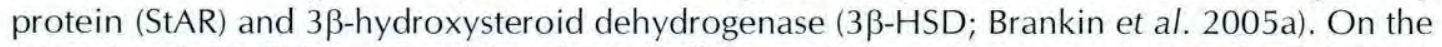
other hand, BMP-6 suppressed androstenedione and progesterone production by the theca cells while BMP-15 increased their progesterone production (Quinn et al. 2004b, Brankin et al. 2005b). Recombinant GDF-9 also decreased FSH-stimulated progesterone production in porcine granulosa cells and its effect was enhanced by androgen (Hickey et al. 2005). BMP-6 and BMP-15 have been shown to increase theca cell viability while BMP-6 and GDF-9 were found to respectively stimulate theca and granulosa cell proliferation (Quinn et al. 2004b, Brankin et al. 2005a, Brankin et al. 2005b, Hickey et al. 2005). Finally, although it still remains to be shown in the pig, GDF-9 increased bovine oocyte developmental competence (Hussein et al. 2006). Overall, the oocyte and oocyte-derived ligands appear to dictate the steroidogenic ability of the cumulus and mural granulosa cells and clearly prevent precocious luteinisation of the follicle. Moreover, their effects on cell proliferation and viability suggest that the oocyte also modulates the growth of healthy antral follicles.

\section{Somatic cell derived BMPS}

Evidence also supports a role for the somatic cell derived BMPs including BMP-2, -4 , and -7 in antral follicle development but the information available in mammals and in pigs is limited. Their localisation in the ovary is perhaps the first clue that these molecules act as paracrine and autocrine modulators of ovarian functions. In the porcine follicle, BMP-2 mRNA and protein was found to be expressed by the granulosa and theca cells throughout the follicular phase (Brankin et al. 2005a, Paradis et al. 2009). In addition, BMP-4 and BMP-7 

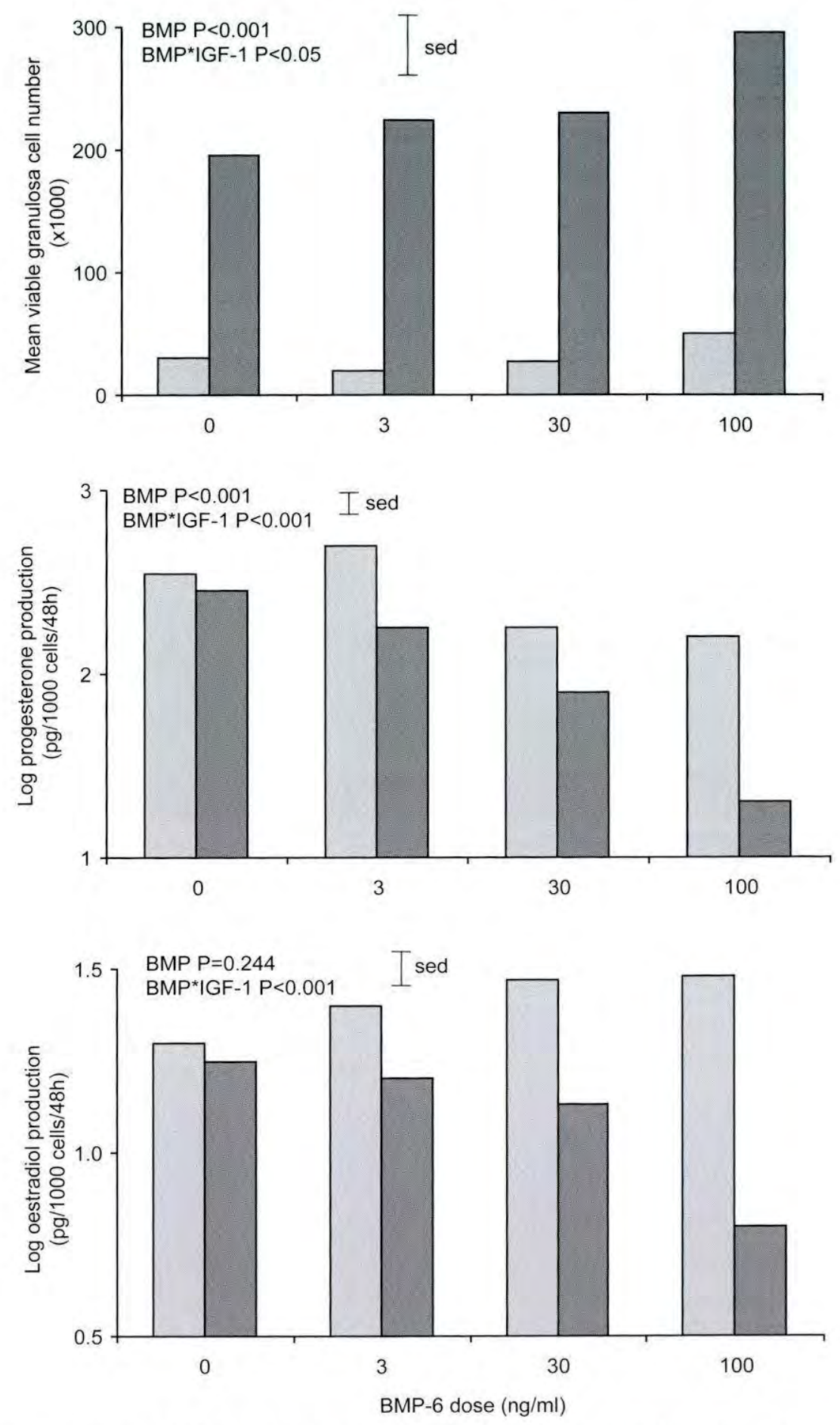

Fig. 2 The effect of BMP-6 on (a) mean $( \pm$ sed) viable granulosa cell number (b) mean $( \pm$ sed) $\log _{10}$ progesterone production by granulosa cells and (c) mean ( \pm sed) $\log _{10}$ oestradiol production by granulosa cells after 144 hours in serum free culture in the absence ( $\square$ ) and presence $(\square)$ of $100 \mathrm{ng} / \mathrm{ml} \mathrm{IGF-1.} \mathrm{Values} \mathrm{are} \mathrm{from} 3$ independent cultures. 
were reported to be expressed exclusively by the theca cells of rat and bovine antral follicles (Erickson \& Shimasaki 2003, Glister et al. 2004). As for the oocyte derived BMPs, every cell type in the follicle is a potential target for BMP-2, -4, and 7 since they signal through the same type I and type II receptors.

In the porcine antral follicle, only BMP-2 has been tested for its ability to promote granulosa and theca cell steroidogenesis, and cell proliferation and viability (Brankin et al. 2005a,b). Its action on the theca cells is remarkably similar to that of BMP-6, as it reduces progesterone, androstenedione and oestradiol production. It also suppressed granulosa cell progesterone production in a dose-dependent manner. Finally, perhaps of more interest is the action of the theca cell specific BMP-4 and BMP-7 on granulosa cell and theca cell function. In bovine theca cells, BMP-4 and BMP-7 decreased androstenedione production while they increased oestradiol, inhibin A, activin A and follistatin secretion by the granulosa cells (Glister et al. 2004 , 2005). This is particularly interesting because follistatin, which is known to bind activin with high affinity, was also found to counteract the effect of many BMPs (Glister et al. 2004, 2005). Other binding proteins including chordin and gremlin have also been reported to counteract the effect of specific BMP proteins (Glister et al. 2005, Juengel \& McNatty 2005). This observation sheds some light on how the autocrine and paracrine BMP signalling pathways are regulated in the ovarian follicle but also creates another level of complexity, demonstrating that the different TGF- $\beta$ subfamilies interact together and also with other growth factor families (such as IGF-1, c-kit-KitL).

It is interesting to note that the functions of the BMPs on steroidogenesis and cell proliferation (Fig. 4) are somewhat redundant and they clearly act in concert to prevent precocious luteinisation of the follicle. They also promote cell proliferation, but whether they have a role in regulating ovulation rate in the pig, as in sheep, is currently unknown. The observation that the oocyte appears to directly control the steroidogenic and metabolic activity of the cumulus cells suggests that the gradient of oocyte-derived BMPs may be involved in establishing the cumulus cell versus mural granulosa cell phenotype.

\section{TGF- $B$ and associated receptors}

The TGF- $\beta$ subfamily is comprised of three ligands namely TGF- $B 1,-\beta 2$ and $-B 3$ and two associated receptors, TGFßRI (also known as ALK5) and TGFBRII (ten Dijke \& Hill 2004, Juengel \& MCNatty 2005). Betaglycan (also known as TGFßRIII) has also been shown to be necessary for binding of TGF-ß2 in many cell types (ten Dijke \& Hill 2004). In porcine follicles, the theca interna appears to be the primary source of TGF- $\beta$ and TGF- $\beta 1$ accounts for most of the TGF- $\beta$ bioactivity on cell proliferation (May et al. 1996). Similarly, TGF-ß3 appears most prominent in the theca cells of large antral follicles, but its functions have yet to be established (May et al. 1996, Steffl et al. 2008). The expression of the TGF-ß receptors in the porcine ovary has been less extensively studied than their ligands but Goddard et al. (1995) reported that cultured granulosa cells expressed TGFBRI, TGFBRII and TGFBRIII mRNA and produced the protein for TGBßR1 and TGFßRII. However, since granulosa cells tend to luteinize in culture, particularly in presence of serum, these results may reflect the ability of luteal, rather than follicular, cells to respond to the TGF- $B$ ligand. Nevertheless, we detected the expression of TGFBR1 mRNA in antral follicles throughout the follicular phase and also in the final preovulatory population pre- and post-LH surge. Our findings confirmed that TGFßR1 mRNA is present in the oocyte, granulosa cells and theca cells of antral follicles at all stages studied (Paradis et al. 2009). Our results also showed that both granulosa and theca cell derived TGFBR 1 mRNA increased during the mid-selection phase and remained constant until the preovulatory LH surge (Fig. 3), 
suggesting the involvement of one of its ligands in follicle selection and in the maintenance of the preovulatory follicle population.
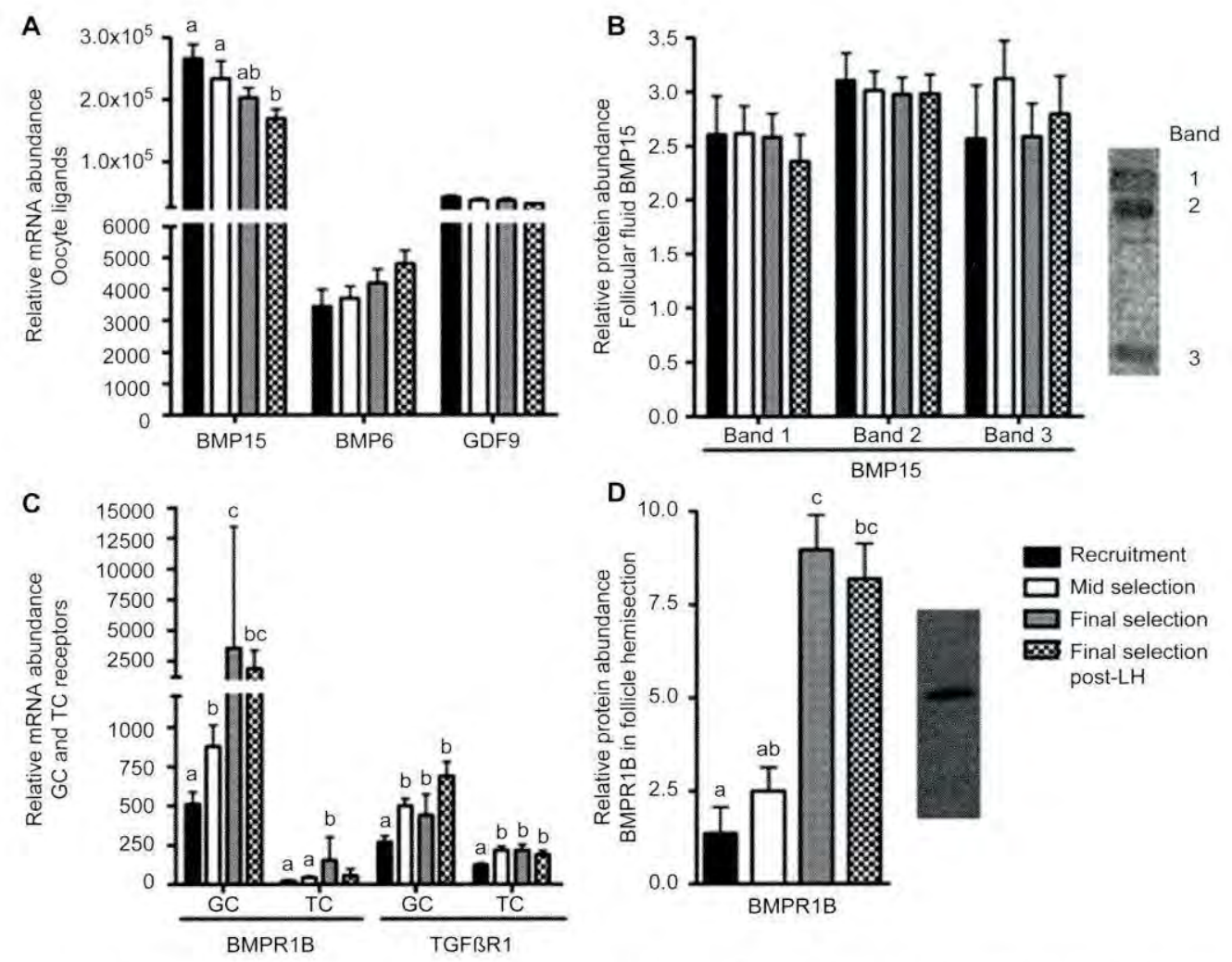

Fig. 3 Temporal changes in the mRNA abundance of (A) oocyte-derived ligands and (C) their corresponding receptors in granulosa (GC) and theca cells (TC) during the porcine follicular phase. (B) represents the corresponding changes in protein abundance of BMP15 in the follicular fluid and (D) of BMPR1B in follicle hemisections. Data are expressed as relative abundance \pm SEM. Different superscripts within gene represent significant differences between phases $(P \leq 0.05)$.

The effects of the TGF- $ß$ proteins on ovarian cells have been mainly associated with cell proliferation and differentiation (ie. steroidogenesis). TGF-ß1 and TGF-ß2 both inhibited basal- and growth factor-stimulated porcine granulosa cell proliferation while having little effect on theca cells (Mondschein et al. 1988). In addition, TGF-ß1 decreased both basal and $\mathrm{FSH}$-stimulated aromatase activity while the converse was observed in theca cells (Caubo et al. 1989, Goddard et al. 1995). TGF-B1 also inhibited both basal and FSH or LH -stimulated progesterone production in cultured granulosa or theca cells respectively (Mondschein et al. 1988, Caubo et al. 1989, Engelhardt et al. 1992). The inhibitory effect observed on theca cell progesterone production is believed to occur upstream of P450scc (Engelhardt et al. 1992) and interestingly, TGF-ß1 and TGF-ß2 inhibited hCG binding to granulosa cells (Gitay-Goren et al. 1993). These observations suggest that the TGF- $\beta$ subfamily may mediate the steroidogenic activity of the granulosa cells and potentially of the theca cells (Fig. 4) through direct regulation of the gonadotrophin receptors. On the other hand, TGF- 31 has also been shown to interact 
with the IGF system in granulosa cells (Mondschein et al. 1990) which in turn could indirectly influence the steroidogenic activity of those cells. Collectively, these observations suggest that the TGF- $\beta$ subfamily is important for modulating the rate of follicle growth while preventing precocious luteinisation of the follicle (Fig. 4).

\section{The periovulatory period}

The LH surge triggers a series of events leading to ovulation, luteinisation of the mural granulosa cell and theca cells, cumulus cell expansion and oocyte meiotic resumption (Richards et al. 2002). Although gap-junctional communication has been postulated to propagate the signal from the LH responsive mural granulosa cells to the cumulus cells and oocyte, increasing evidence suggests that paracrine signalling from the mural granulosa cells is also important. This section will address the roles of the BMPs and the EGF/EGF-like ligands during the periovulatory period.

\section{The bone morphogenetic proteins (BMPs)}

Cumulus cell expansion is a necessary event for ovulation (Richards et al. 2002) and in the mouse, the oocyte is required for FSH to stimulate cumulus expansion and hyaluronic acid synthesis (Salustri et al. 1990). The factor(s) responsible for cumulus cell expansion, named cumulus expansion-enabling factor (CEEF) is also produced by porcine oocyte (Singh et al. 1993) but appears dispensible for porcine cumulus cells expansion and production of hyaluronic acid (Prochazka et al. 1991, Singh et al. 1993, Nagyova et al. 1999). Interestingly, Prochazka et al. (1998) demonstrated that porcine cumulus and mural granulosa cells also produce the CEEF.

The identity of the CEEF still remains a controversial topic however, BMP-15 and GDF-9 represent prime candidate to fulfill this function. First of all, oocytes deficient in GDF-9 fail to stimulate cumulus expansion and the genes necessary for that process (Vanderhyden et al. 2003) and recombinant GDF-9 has been shown to promote mouse cumulus expansion and induce hyaluronan synthase 2 (HAS2) expression (Elvin et al. 1999). On the other hand, Bmp-15 null mice have a decreased ovulation rate while the Bmpr $1 b$ null mice exhibited defective cumulus expansion (Yan et al. 2001, Yi et al. 2001, Su et al. 2004). In addition, the mature form of BMP-15 appears during the periovulatory period in the mouse, following gonadotrophin stimulation (Yoshino et al. 2006, Gueripel et al. 2006). Unfortunately, recombinant BMP-15 has yet to be tested for its ability to promote cumulus expansion, and hyaluronic acid synthesis and its related genes. In the pig, both BMP-15 and GDF-9 mRNA and protein were detected in the oocyte, cumulus and mural granulosa cells, convincingly demonstrating the potential for those cell types to promote cumulus cell expansion (Prochazka et al. 2004, Lee et al. 2008, Paradis et al. 2009). Although no concomitant increase in GDF-9 mRNA was observed during porcine cumulus cell expansion, it does not preclude the possibility that post-translational modification or processing could regulate the bioactivity of GDF-9 (Prochazka et al. 2004). Similarly, Paradis et al. (2009) showed that although the abundance of BMP-15 did not change dramatically during follicle development, the expression of BMPR1B in the granulosa cells (combined cumulus and mural granulosa cells) increased in the periovulatory period (Fig. 3) suggesting a role for this ligand in preparation for ovulation. The direct effect of recombinant GDF-9 or BMP-15 on porcine cumulus expansion has yet to be reported but could shed the light on how the ovulatory process is regulated in the porcine follicle. 


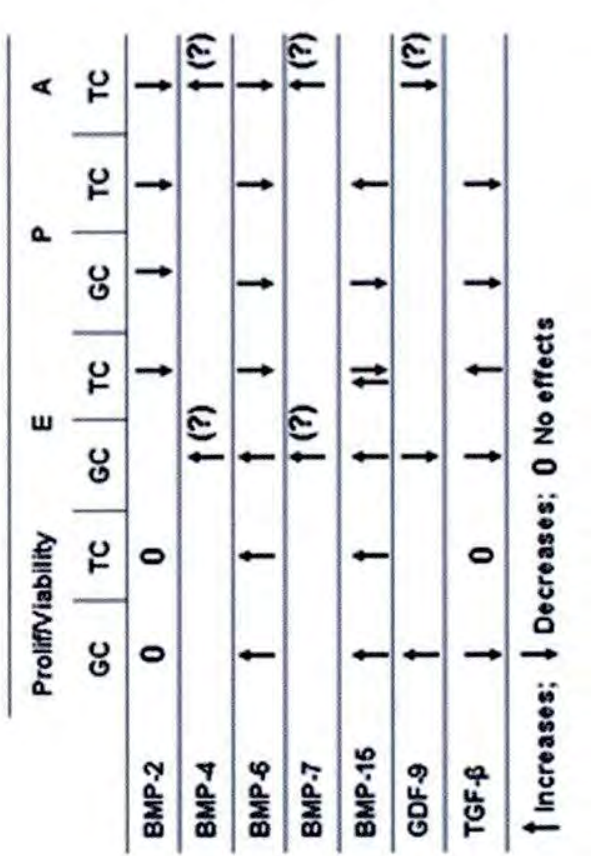

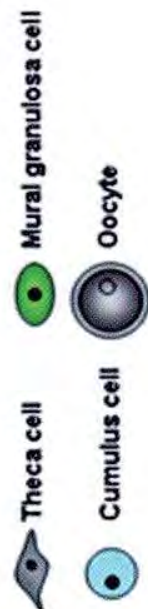

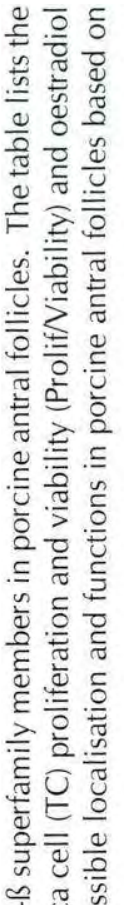

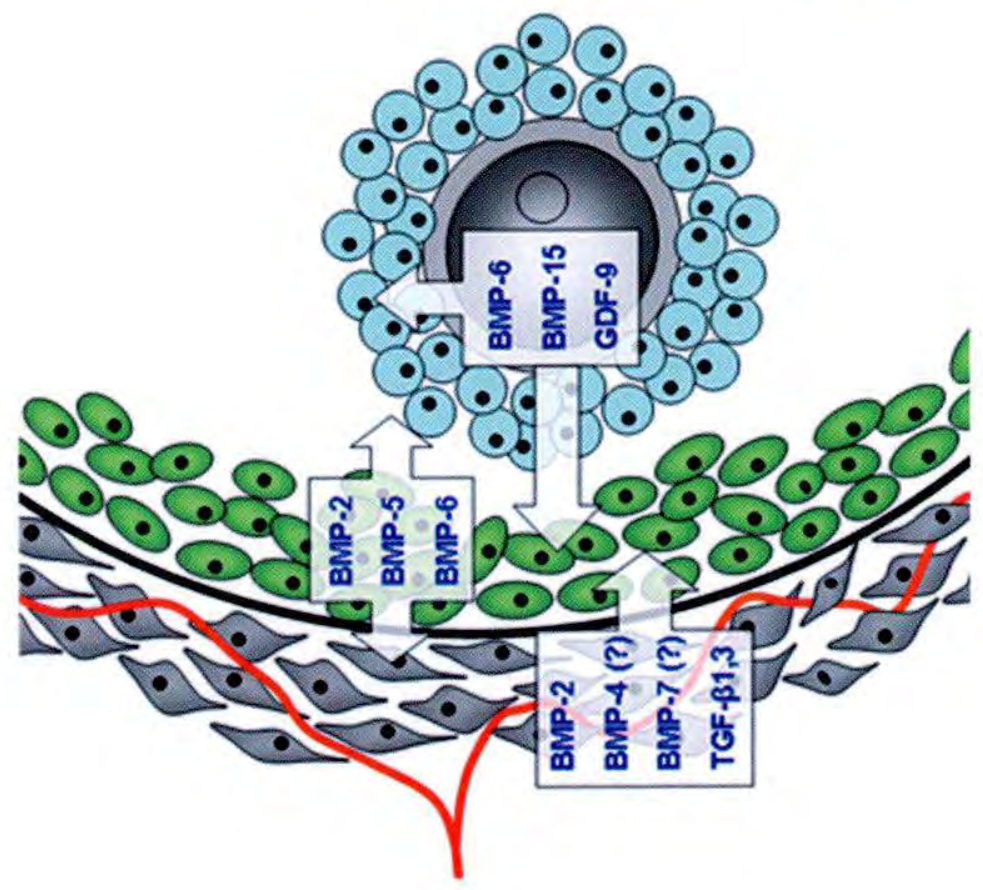

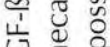

$\div \pm \frac{1}{5}$

워

응 তِ

ป

흐는

을 함

총

으 등 के

늘

士

을

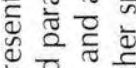

응 흥

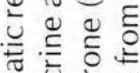

हृ

论

$+\sum$ 흉

这立岀。 


\section{EGF and EGF-like peptides}

The epidermal growth factor family includes many closely related proteins including EGF, amphiregulin, epiregulin and betacellulin (Conti et al. 2006). These ligands signal through the EGF receptors, including EGFR (ErbB1), belonging to tyrosine kinase receptor family. The effect of EGF on cumulus and oocyte function in culture has been well studied in several species and the roles of amphiregulin, epiregulin and betacellulin are becoming evident.

In porcine follicles, EGF appears to be predominantly expressed in the mural granulosa cells although it has been also detected at much lower level in the oocyte and cumulus cells (Singh et al. 1995). The EGFR was detected in the cumulus and mural granulosa cells as well as in the theca cells, suggesting that most effects on the oocyte occur indirectly through the cumulus cells. EGF potently stimulates porcine cumulus cell expansion in vitro and interestingly, the ability of the porcine cumulus cells to undergo expansion increases with follicle size and is linked to the FSH-enhanced ability of those cells to activate the EGF receptor (Prochazka et al. 2000, 2003). Furthermore, EGF supplementation enhances oocyte nuclear maturation and oocyte developmental competence in vitro (Reed et al. 1993, Prochazka et al. 2000).

More recently, a group of EGF-like ligands namely amphiregulin (AREG), epiregulin (EREG) and betacellulin (BTC) have been found to mediate $\mathrm{LH}$ action in the mouse follicle (Park et al. 2004). All three factors stimulated oocyte meiotic resumption in a whole follicle culture system in a manner similar to $\mathrm{LH}$, although their action appeared to be downstream of $\mathrm{LH}$ (Park et al. 2004). Interestingly, LH- but not AREG-, EREG- or BTC-stimulated cumulus cell expansion was abolished when cumulus-oocyte complexes rather than whole follicles were used, suggesting that $\mathrm{LH}$ regulation of cumulus cell expansion and oocyte meiotic resumption occurs indirectly through mural granulosa cells. Moreover, the effects of the EGF-like ligands on the COC are believed to occur via the cumulus cells, as denuded oocytes did not resume meiosis. Further convincing evidence for the involvement of these three factors in cumulus expansion was that all three EGF-like ligands induced HAS2 mRNA in the same way as LH (Park et al. 2004, Shimada et al. 2006). Finally, the effect of AREG, EREG and BTC was shown to occur through the EGFR since the EGFR kinase inhibitor AG1478 completely prevented their effects. Similar observations have been made in porcine COC (Yamashita et al. 2007, Chen et al. 2008). Another interesting aspect is that AREG and EREG are expressed as transmembrane precursors and require metalloprotease activity to be released and to activate the EGFR on the target cells (Dong et al. 1999). In cultured porcine COC, mRNA expression and activity of TACE/ ADAM17 metalloprotease was induced by FSH and LH in similar manner to that of AREG and EREG (Yamashita et al. 2007). Metalloprotease inhibitor prevented cumulus expansion while EGF completely reversed this inhibitory effect. From these results, the authors concluded that TACE/ADAM17 metalloprotease is required for the release of the membrane bound EGF-like ligand and EGFR-mediated activation of cumulus cell expansion and oocyte meiotic maturation (Yamashita et al. 2007). Finally, it remains to be established whether there is an interaction between the TGF- $B$ superfamily and the EGF system in the regulation of the periovulatory events leading to ovulation.

\section{Conclusions}

It is clear that follicle development (from primordial to pre-ovulatory follicle) and acquisition of oocyte developmental competence involves the interaction of an ever increasing number of local growth factors. Paracrine interactions occur within the somatic cells and also between the somatic cells and the oocyte in a bi-directional manner, all of which are essential for normal follicular development. These local factors, along with endocrine hormones, act to 
regulate steroidogenesis, proliferation, differentiation, apoptosis, cumulus expansion, oocyte maturation and developmental potential. Although our knowledge of these intra-follicular regulatory factors, particularly members of the TGF- $B$ superfamily, has increased dramatically in recent years, there are still unanswered questions including how the temporal and spatial expression of these factors is regulated, why there appears to be redundancy of some of the ligands and precisely how the various growth factor families interact in the growing follicle. Furthermore, much of the information discussed in this review has been generated from in vitro or localisation studies, or by extrapolation from other species and whilst such information is extremely valuable, particularly from a mechanistic viewpoint, there is still a need to understand precisely how these factors interact in vivo. Therefore the testing of some of the hypothesised roles of these paracrine hormones in animal models should be a high priority to help unravel their relative importance in regulating follicle development in the pig. It is only through increased understanding of the precise roles of these intra-follicular factors, that further improvements in reproductive efficiency will be made.

\section{Acknowledgements}

MGH acknowledges funding from BBSRC (42/S17232). FP acknowledges funding from NSERC and Alberta Ingenuity.

\section{References}

Bodensteiner KJ, Clay CM, Moeller CL \& Sawyer HR 1999 Molecular cloning of the ovine growth/differentiation factor -9 gene and expression of growth/differentiation factor -9 in ovine and bovine ovaries. Biology of Reproduction 60 381-386.

Brankin V, Mitchell MR, Webb B \& Hunter MG 2003a Paracrine effects of oocyte secreted factors and stem cell factor on porcine granulosa and theca cells in vitro. Reproductive Biology and Endocrinology 155.

Brankin V, Quinn RL, McGarr C, Webb R \& Hunter MG 2003b BMPs 2, 6 and 15 are regulators of porcine granulosa cell function in vitro. Reproduction Abstract Series 3094

Brankin V, Hunter MG, Horan TL, Armstrong DG \& Webb R 2004 The expression patterns of mRNAencoding stem cell factor, internal stem cell factor and c-kit in the prepubertal and adult porcine ovary. Journal of Anatomy 205 393-403.

Brankin V, Quinn RL, Webb R \& Hunter MG 2005a Evidence for a functional bone morphogenetic protein (BMP) system in the porcine ovary. Domestic Animal Endocrinology 28 367-379.

Brankin V, Quinn RL, Webb R \& Hunter MG 2005b BMP-2 and -6 modulate porcine theca cell function alone and co-cultured with granulosa cells. Domestic Animal Endocrinology 29 593-604.

Caubo B, Devinna RS \& Tonetta SA 1989 Regulation of steroidogenesis in cultured porcine theca cells by growth-factors. Endocrinology 125 321-326.

Chen X, Zhou B, Yan J, Xu B, Tai P, Li J, Peng S, Zhang M \& Xia G 2008 Epidermal growth factor receptor activation by protein kinase $C$ is necessary for $\mathrm{FSH}$ induced meiotic resumption in porcine cumulus- oocyte complexes. Journal of Endocrinology 197 409-419.

Clark DE, Tisdall D), Fidler AE \& MCNatty KP 1996 Localisation of mRNA encoding c-kit during the initiation of folliculogenesis in ovine fetal ovaries. Journal of Reproduction and Fertility 106 329-335.

Conti M, Hsieh M, Park JY \& Su YQ 2006 Role of the epidermal growth factor network in ovarian follicles. Molecular Endocrinology 20 715-723.

Coskun S, Uzumcu M, Lin YC, Friedman Cl \& Alak BM 1995 Regulation of cumulus cell steroidogenesis by the porcine oocyte and preliminary characterization of oocyte-produced factor(s). Biology of Reproduction $53670-675$.

Dong JW, Albertini DF, Nishimori K, Kumar TR, Lu NF \& Matzuk MM 1996 Growth differentiation factor-9 is required during early ovarian folliculogenesis. Nature 383531.535.

Dong J, Opresko LK, Dempsey PJ, Lauffenburger DA, Coffey RJ \& Wiley HS 1999 Metalloprotease-mediated ligand release regulates autocrine signaling through the epidermal growth factor receptor. Proceedings of the National Academy of Sciences U S A 96 6235-6240.

Durlinger AL, Gruijters MJ, Kramer P, Karels B, Ingraham HA, Nachtigal MW, Uilenbroek IT, Grootegoed JA \& Themman AP 2002 Anti-Mulleriam hormone inhibits initiation of primordial follicle growth in the mouse ovary. Endocrinology 143 1076-1084

Elvin JA, Clark AT, Wang P, Wolfman NM \& Matzuk MM 1999 Paracrine actions of growth differentiation factor-9 in the mammalian ovary. Molecular Endocrinology 13 1035-1048. 
Elvin JA, Yan C \& Matzuk MM 2000 oocyte-expressed TGF-beta superfamily members in female fertility. Molecular and Cellular Endocrinology 159 1-5.

Engelhardt $H$, Tekpetey FR, Gore-Langton RE \& Armstrong DT 1992 Regulation of steroid production in cultured porcine thecal cells by transforming growth factor-beta. Molecular and Cellular Endocrinology 85 117-126.

Eppig J), Pendola FL, Wigglesworth K \& Pendola JK 2005 Mouse oocytes regulate metabolic cooperativity between granulosa cells and oocytes: amino acid transport. Biology of Reproduction 73 351-357.

Erickson GF \& Shimasaki S 2003 The spatiotemporal expression pattern of the bone morphogenic protein family in rat ovary cell types during the estrous cycle. Reproductive Biology and Endocrinology 19.

Galloway SM, McNatty KP, Cambridge LM, Laitinen MPE, Juengel JL, Sakari Jokiranta T, McLaren RJ, Luiro K, Dodds KG et al 2000 Mutations in an oocytederived growth factor gene (BMP15) cause increased ovulation rate and infertility in a dosage-sensitive manner. Nature Cenetics 25 279-283

Gilchrist RB, Lane M \& Thompson JG 2008 Oocytesecreted factors: regulators of cumulus cell function and oocyte quality. Human Reproduction Update 14 159-177.

Gitay-Goren H, Kim IC, Miggans ST \& Schomberg DW 1993 Transforming growth factor beta modulates gonadotropin receptor expression in porcine and rat granulosa cells differently. Biology of Reproduction 48 1284-1289.

Glister C, Kemp CF \& Knight PG 2004 Bone morphogenetic protein (BMP) ligands and receptors in bovine ovarian follicle cells: actions of BMP-4, -6 and -7 on granulosa cells and differential modulation of Smad-1 phosphorylation by follistatin. Reproduction 127 239-254.

Glister C, Richards SL \& Knight PG 2005 Bone morphogenetic proteins (BMP) $-4,-6$, and -7 potently suppress basal and luteinizing hormone-induced androgen production by bovine theca interna cells in primary culture: could ovarian hyperandrogenic dysfunction be caused by a defect in thecal BMP signaling? Endocrinology 146 1883-1892.

Goddard I, Hendrick IC, Benahmed M \& Morera AM 1995 Transforming growth factor beta receptor expression in cultured porcine granulosa cells. Molecular and Cellular Endocrinology 115 207-213.

Gueripel X, Brun V \& Gougeon A 2006 Oocyte bone morphogenetic protein 15 , but not growth differentiation factor 9 , is increased during gonadotropin-induced follicular development in the immature mouse and is associated with cumulus oophorus expansion. Biology of Reproduction 75 836-843.

Hickey TE, Marrocco DL, Amato F, Ritter LJ, Norman RJ, Gilchrist RB \& Armstrong DT 2005 Androgens augment the mitogenic effects of oocyte-secreted factors and growth differentiation factor 9 on porcine granulosa cells. Biology of Reproduction 73 825-832.
Hussein TS, Thompson IG \& Gilchrist RB 2006 Oocytesecreted factors enhance oocyte developmental competence. Developmental Biology 296 514-521.

Juengel JL. \& MCNatty KP 2005 The role of proteins of the transforming growth factor-beta superfamily in the intraovarian regulation of follicular development. Human Reproduction Update 11 143-160.

Keshet E, Lyman SD \& Williama DE 1991 Embryonic RNA expression patterns of the c-kit receptor and its cognate ligand suggest multiple functional roles in mouse development. EMBO lournal 10 2425-2435

Klinger FG \& de Felicic M 2002 in vitro development of growing oocytes from fetal mouse oocytes: stage specific regulation by stem cell factor and granulosa cells. Developmental Biology 244 85-95.

Knight PG \& Glister C 2006 TGF-ß superfamily members and ovarian follicle development. Reproduction 132 191-206

Lee GS, Kim HS, Hwang WS \& Hyun SH 2008 Characterization of porcine growth differentiation factor-9 and its expression in oocyte maturation. Molecular Reproduction and Development 75 707-714.

Lee WS, Otsuka F, Moore RK \& Shimasaki S 2001 Effects of bone morphogenetic protein-7 on folliculogenesis and ovulation in the rat. Biology of Reproduction 65 994-999.

McNatty KP, Smith P, Moore LG, Reader K, Lun S, Hanrahan IP, Groome NP, Latinen M, Ritvos O \& luengel JL 2005 Oocyte-expressed genes affecting ovulation rate. Molecular and Cellular Endocrinology 234 57-66.

May JV, Stephenson LA, Turzcynski CJ, Fong HW, Mau YH \& Davis IS 1996 Transforming growth factor beta expression in the porcine ovary: evidence that theca cells are the major secretory source during antral follicle development. Biology of Reproduction 54 485-496.

Miyazono K, Kusanagi K, Inoue H 2001 Divergence and convergence of TGF-beta/BMP signalling. Journal of Cellular Physiology 187 265-76.

Mondschein JS, Canning SF \& Hammond JM 1988 Effects of transforming growth factor-beta on the production of immunoreactive insulin-like growth factor $I$ and progesterone and on [3H]thymidine incorporation in porcine granulosa cell cultures. Endocrinology 123 $1970-1976$.

Mondschein JS, Smith SA \& Hammond IM 1990 Production of insulin-like growth factor binding proteins (IGFBPs) by porcine granulosa cells: identification of ICFBP-2 and -3 and regulation by hormones and growth factors. Endocrinology 127 2298-2306.

Moniruzzaman M \& Miyano T 2007 KIT-KIT ligand in the growth of porcine oocytes in primordial follicles. lournal of Reproduction and Development 53 1273-1281

Nagyova E, Prochazka R \& Vanderhyden BC 1999 Oocytectomy does not influence synthesis of hyaluronic acid by pig cumulus cells: retention of hyaluronic acid after insulin-like growth factor-I treatment in serum-free 
medium. Biology of Reproduction 61 569-574.

Nilsson EE \& Skinner MK 2002 Growth and differentiation factor-9 stimulates progression of early primary but not primordial rat ovarian follicle development. Biology of Reproduction 67 1018-1024

Nilsson EE \& Skinner MK 2003 Bone morphogenetic protein-4 acts as an ovarian follicle survival factor and promotes primordial follicle development. Biology of Reproduction 69 1265-1272

Nilsson EE \& Skinner MK 2004 Kit ligand and basic fibroblast growth factor interactions in the induction of ovarian primordial to primary follicle transition. Molecular and Cellular Endocrinology 214 19-25.

Nilsson E, Rogers N \& Skinner MK 2007 Actions of antiMullerian hormone on the ovarian transcriptome to inhibit primordial to primary follicle transition. Reproduction 134 209-221.

Oxender WD, Colenbrander B, van deWiel DF \& Wensing Cl 1979 Ovarian development in fetal and prepubertal pigs. Biology of Reproduction 21 715.721

Packer Al, Hsu YC, Besmer P \& Bachvarova RF 1994 The ligand of the c-kit receptor promotes oocyte growth. Developmental Biology 161 194-205

Paradis F, Novak S, Murdoch CK, Dyck MK, Dixon WT \& Foxcroft GR 2009 Temporal regulation of BMP2, BMP6, BMP15, GDF-9, BMPR1A, BMPR1B, BMPR2 and TCFBR1 mRNA expression in the oocyte, granulosa and theca cells of developing preovulatory follicles in the pig. Reproduction 138.

Park JY, Su YQ, Ariga M, Law E, Jin SL \& Conti M 2004 ECF-like growth factors as mediators of $\mathrm{LH}$ action in the ovulatory follicle. Science 303 682-684.

Parrott JA \& Skinner MK 1999 Kit ligand/Stem cell factor induces primordial follicle development and initiates folliculogenesis. Endocrinology 140 4262-4271

Prochazka R, Nagyova E, Rimkevicova Z, Nagai T, Kikuchi K \& Motlik J 1991 Lack of effect of oocytectomy on expansion of the porcine cumulus. Journal of Reproduction and Fertility 93 569-576.

Prochazka R, Nagyova E, Brem G, Schellander K \& Motlik J 1998 Secretion of cumulus expansion-enabling factor (CEEF) in porcine follicles. Molecular Reproduction and Development 49 141-149.

Prochazka R, Srsen V, Nagyova E, Miyano T \& Flechon IE 2000 Developmental regulation of effect of epidermal growth factor on porcine oocyte-cumulus cell complexes: nuclear maturation, expansion, and F-actin remodeling. Molecular Reproduction and Development 56 63-73.

Prochazka R, Kalab P \& Nagyova E 2003 Epidermal growth factor-receptor tyrosine kinase activity regulates expansion of porcine oocyte-cumulus cell complexes in vitro. Biology of Reproduction 68 797-803.

Prochazka R, Nemcova L, Nagyova E \& Kanka J 2004 Expression of growth differentiation factor 9 messenger RNA in porcine growing and preovulatory ovarian follicles. Biology of Reproduction 71 1290-1295.

Quinn RL, Shuttleworth G \& Hunter MG 2002 Localization of bone morphogenic protein (BMP)-15 mRNA and BMP receptors in the porcine ovary. Biology of Reproduction
66 supplement 132 .

Quinn RL, Shuttleworth G \& Hunter MG 2004a Immunocytochemical localisation of the bone morphogenetic protein in the porcine ovary. Journal of Anatomy 205 15-23.

Quinn RL, Brankin V, McGarr C, Webb R \& Hunter MC $2004 \mathrm{~b}$ BMPs 2, 6 and 15 are regulators of porcine theca cell function in vitro Reproduction. Abstract Ser 31:44

Reed ML, Estrada JL, Illera MJ \& Petters RM 1993 Effects of epidermal growth factor, insulin-like growth factor-1, and dialyzed porcine follicular fluid on porcine oocyte maturation in vitro. Journal of Experimental Zoology 266 74-78.

Richards JS, Russell DL, Ochsner S \& Espey LL 2002 Ovulation: New dimensions and new regulators of the inflammatory-like response. Annual Review of Physiology 64 69-92.

Salustri A, Yanagishita M \& Hascall VC 1990 Mouse oocytes regulate hyaluronic acid synthesis and mucification by FSH-stimulated cumulus cells. Developmental Biology 138 26-32.

Shimada M, Hernandez-Gonzalez I, Gonzalez-Robayna I \& Richards JS 2006 Paracrine and autocrine regulation of epidermal growth factor-like factors in cumulus oocyte complexes and granulosa cells: key roles for prostaglandin synthase 2 and progesterone receptor. Molecular Endocrinology 20 1352-1365.

Shimasaki S, Moore RK, Otsuka F \& Erickson GF 2004 The bone morphogenetic protein system in mammalian reproduction. Endocrine Reviews 25 72-101

Shimizu T, Yokoo M, Miyake Y, Sasada H \& Sato E 2004a Differential expression of bone morphogenetic protein 406 (BMP-4, -5 and -6$)$ and growth differentiation factor .9 (CDF-9)during ovarian development in neonatal pigs. Domestic Animal Endocrinology 27 397-405.

Shimizu T, Miyahayashi Y, Yokoo M, Hoshino Y Sasada H \& Sato E 2004b Molecular cloning of porcine growth differentiation factor 9 (GDF-9) CDNA and its role in early folliculogenesis: direct ovarian injection of GDF-9 gene fragments promotes early folliculogenesis. Reproduction 128 537-543

Singh B, Zhang X \& Armstrong DT 1993 Porcine oocytes release cumulus expansion-enabling activity even though porcine cumulus expansion in vitro is independent of the oocyte. Endocrinology 132 1860-1862.

Singh B, Rutledge JM \& Armstrong DT 1995 Epidermal growth factor and its receptor gene expression and peptide localization in porcine ovarian follicles. Molecular Reproduction and Development $\mathbf{4 0}$ 391-399.

Steffl M, Schweiger M \& Amselgruber WM 2008 Expression of transforming growth factor-beta3 (TCFbeta3) in the porcine ovary during the oestrus cycle. Histology and Histopathology 23 665-671.

Su YQ, Wu X, O'Brien MJ, Pendola FL, Denegre IN, Matzuk MM \& Eppig II 2004 Synergistic roles of BMP15 and GDF9 in the development and function of the oocyte-cumulus cell complex in mice: genetic evidence for an oocyte-granulosa cell regulatory loop. 
Developmental Biology 276 64-73.

ten Dijke P \& Hill CS 2004 New insights into TGF-betaSmad signalling. Trends in Biochemical Science 29 265-273.

Thomas FH \& Vanderhyden BC 2006 Oocyte-granulosa cell interactions during mouse follicular development: regulation of kit ligand expression and its role in oocyte growth. Reproductive Biology and Endocrinology 4 19.

Vanderhyden BC, Macdonald EA, Nagyova E \& Dhawan A 2003 Evaluation of members of the TGFbeta superfamily as candidates for the oocyte factors that control mouse cumulus expansion and steroidogenesis. Reproduction Supplement 61 55-70.

Visser IA \& Themmen AP 2005 Anti-Mullerian hormone and folliculogenesis. Molecular and Cellular Endocrinology 234 81-86.

Yamashita Y, Kawashima I, Yanai Y, Nishibori M, Richards IS \& Shimada M 2007 Hormone-induced expression of tumor necrosis factor alpha-converting enzyme/A disintegrin and metalloprotease-1 7 impacts porcine cumulus cell oocyte complex expansion and meiotic maturation via ligand activation of the epidermal growth factor receptor. Endocrinology 148 6164-6175.
Yan C, Wang P, DeMayo J, DeMayo FI, Elvin JA, Carino C, Prasad SV, Skinner SS, Dunbar BS, Dube IL, Celeste A) \& Matzuk MM 2001 Synergistic roles of bone morphogenetic protein 15 and growth differentiation factor 9 in ovarian function. Molecular Endocrinology 15 854-866.

Yi SE, LaPolt PS, Yoon BS, Chen JY, Lu JK \& Lyons KM 2001 The type I BMP receptor $8 \mathrm{mprlB}$ is essential for female reproductive function. Proceedings of the National Academy of Science U S A 98 7994-7999.

Yoshino O, McMahon HE, Sharma S \& Shimasaki S $2006 \mathrm{~A}$ unique preovulatory expression pattern plays a key role in the physiological functions of BMP-15 in the mouse. Proceedings of the National Academy of Science U S A 103 10678-10683.

Yuan W, Lucy MC \& Smith MF 1996 Messenger ribonucleic acid for insulin-like growth factors-1 and -11 , insulin-like growth factor-binding protein-2, gonadotropin receptors, and steroidogenic enzymes in porcine follicles. Biology of Reproduction $\mathbf{5 5}$ 1045-1054.

Zhu G, Guo B, Pan D, Mu Y \& Feng S 2008 Expression of bone morphogenetic proteins and receptors in porcine cumulus-oocyte complexes during in vitro maturation. Animal Reproduction Science 104 275-283. 